\title{
A Cross-cultural Analysis of the Pragmatic Differences of English \& Chinese Vocabulary
}

\author{
Xiang Li \\ School of Foreign Studies \\ North China University of Water Resources and Electric Power \\ Zhengzhou, 450046 China
}

\begin{abstract}
As vocabulary is the most active element in a language, it is critical to study the cultural connotations of vocabulary and understand the target culture in intercultural communication. An all-round analysis is made in this paper from different cultural perspectives about the pragmatic differences between English and Chinese vocabulary in intercultural communication, which is intended to emphasize that only by understanding the cultural connotations of words can we gradually overcome the obstacles in intercultural communication.
\end{abstract}

Keywords: vocabulary; English and Chinese; cross-cultural; pragmatic differences

\section{INTRODUCTION}

\section{A. Specific Words}

Rado, an American linguist, pointed out that the division of the semantic categories is decided by cultures and changes with different cultures. The connotation that exists in one culture may be absent in another. Indeed, some words in the language reflect the unique cultural background of the native people; their peer words do not exist in other languages. For example, the English words such as bottle party, hamburger, sandwich, punk, hippie, drive-in and so on all express the unique cultural characteristics of the English nation. In Chinese there are no corresponding words. In English, "drive-in" is interpreted as a place where customers can be served without getting off, such as "drive-in" restaurant (or theater, bank, post office, etc.). In America, with the accelerated pace of life on wheels, a variety of facilities and services to the car naturally emerged, the generation of word "drive-in" is logical. Similarly, in Chinese, there are many words reflecting unique cultural phenomenon that do not exist in English, such as "Yin", "Yang", "Fengshui", "Laoyoutiao", "Paolongtao, "Jiaozi", "Hundun" and "Tangyuan", etc. In some Chinese-English Dictionary, "Jiaozi" is translated into "dumpling", although popular, but not exact. For example, in the New Webster's Encyclopedic Dictionary of the English Language, the explanation is that a dumping means a small lump of dough enclosing fruit or a savory filling, as of meat and steamed, baked, or fried.

So, dumpling can refer to the "tangyuan" and "jiaozi" in Chinese. There are still differences between dumpling and China's "jiaozi".

\section{B. Words with Unique National Emotion}

Language itself is an important factor causing pragmatic failure. Sometimes, the concepts of English words do not correspond with the meanings native learners expressed in words. In feudal China, dragon and Phoenix are traditional symbols of imperial power. Today these two legendary animals still occasionally appear in the traditional Chinese pattern. Chinese parents often say, "望子成龙, 望女成凤, which means their parents hope their children to be great people", or they want their children to grow up to be successful. While, English people think dragon (Long) is a cruel raging monster, symbol of evil. Therefore, in communication with Englishmen, Chinese people should pay particular attention to the use of the term dragon.

\section{GENERAL COMPARISION OF ENGLISH AND CHINESE WORDS}

\section{A. Kinds of Words in Meaning}

Generally speaking, English and Chinese word meaning differs in the degree of correspondence. They are broadly grouped into the following situations: some English words meaning can be found in the corresponding words in Chinese language. Their meanings are completely equal in any context. Such as: the US State Department, the Pacific Ocean, minibus; some words have only a portion corresponding meaning. They are summarized in the sense of the board and narrow points. That is, in both English and Chinese, the width of word meaning is often different." Such as: Sister means jiejie and meime in chinese, marry means ji and $q u$ in Chinese; yangtai in chinese means balcony, and veranda in English, Likewise, the words shangpin (goods, commodity, merchandise), shi (thing, matter, affair, business) in Chinese. In English there are many ambiguous words, which means they can be each corresponded with several different words or phrases in Chinese. Such as soft word, in general, there are many other meanings in Chinese except for "pleasing word" and "comforting word" corresponding to it.

\section{B. The Matching Ability of Words}

English and Chinese have often different matching ability with words. For example, English verb to do. to do the bed means "make the bed" in Chinese, to do one's hair means "cutting hair", to do one's teeth means "brushing one's teeth". To do the window means "clean the window", to do the room means "housecleaning"; to do the dishes means "wash dishes ", to do one's duty is to play their part, "to do a light" means 
sightseeing ". Thus, in English to do has very broad meanings, it can be used in bed, hair, teeth, window, room, dishes, duty, light. while Chinese will have to separately use the words "pu", "jian", "shua", "ca", "dasao", "xi" etc to match . Similarly, Chinese verbs "kan". kan TV means to watch TV, kan the blackboard means to look at the blackboard, kan movies means to see a film, kan the map means to study the map.with a Chinese word" kan ", we must use several different words to translate on different occasions, which is also subject to the English translation with the habit. Therefore, in order to standardize the language translation, the translator is necessary to pay attention to this difference; the translation must comply with words in English and Chinese habits.

\section{CORRESPONDENCE BETWEEN ENGLISH AND CHINESE WORDS IN CULTURAL CONNOTATION}

To better understand the vocabulary and cultural differences in specific cultural connotations, we can summarize the correspondence between related words in the following categories:

\section{A. Words with the same meaning.}

It's not unusual that the two languages have some common words which have the corresponding meaning either allegedly or culturally. The reason is that we mankind all live on the same earth, and covered almost the same developing stage, our emotion and minds are mutually understood, so there are a lot of similarities in language and culture. Many words that denote the nature and social life are homologous, For example, the English "fox", meaning not only the allegations and Chinese word "huli" in the correspondence, but it also corresponds to the cultural connotation, which is seen to be the symbol of "cunning, treacherous". In English, "he is a fox." is exactly the same with the Chinese "Ta zhen shi ge huli ."

Some Chinese words are borrowed from English, they are naturally corresponding with each other。Such as "luoji" (1ogic)、 tuokouxiu (talk show),kelong (clone)、 chaoshi (supermarket)、 taifeng (typhoon) etc 。

\section{B. Words Different in Cultural Connotation.}

But it is rare that the figurative meaning fit completely corresponding phenomenon. There are a lot of English and Chinese words, whose denotation are corresponding, but their connotation are much different. E.g. in English sentence she is a cat. "cat" is not a "cat", but it refers to "harboring evil intentions of the woman"; In She is a dragon. the "dragon" is by no means "dragon", but it refers to "old age and temper fierce-tempered woman." If we do not understand the cultural connotation of these words, it will cause a serious misunderstanding. Due to the existence of ethnic differences in geography, culture, religion and values, their own unique traditional culture would have an additional effect on the vocabulary itself, the concept has different associative meaning.

But cultural connotations are missing some items in the other language. A common word has a very rich associative meaning in one language and may simply be a sign language in another language. This often leads to barriers in words understanding, resulting in unnecessary misunderstandings. The term daffodil is a symbol of spring in the UK as well as the mood of joy spring brings. The "shuixian" in Chinese is just a flower only. Similarly, the plant "bamboo" is often used in Chinese culture to describe constancy, fortitude and integrity of a character, especially in literature works. As $\mathrm{Ou}$ Yangxiu describes "bamboo is the integrity, it turns greener in the winter"; Shao Ye's "Bamboo refuses apostasy, flowers fragrance," and Lee Cheng's "I always love the bamboo, because it is faithful-evident" are all manifestations that bamboo is faithful. But there is no associative meaning of the "bamboo" word in English, because the term bamboo borrowed from Malay. Another reason is that English is not a native Britons for bamboo, it is not as familiar as to the Chinese people, which also determine the term bamboo poor cultural connotations.

\section{Lexical Gaps}

Due to differences in language and culture, there is a great difficulty for some words in finding the corresponding word in another language (equivalents). We call this lack of vocabulary items (lexical gaps)). Vocabulary gap between languages is a very common and natural phenomenon. For example, in English, "crown" symbolizes "royalty", but in Chinese, it refers to the "official positions" on behalf of "official." Another example is the ancient Chinese in the "day" and "month" collectively. They are called the "black rabbit". Because the ancient Han Chinese mythology says Japan has black, mid-rabbit; the sun and the moon were called "black gold" and "rabbit". Such words are rooted in myths and legends of the Han nationality. The metaphor is entirely a product of the imagination of the Chinese nation. Similarly, some English words are simply a product of Western culture, such as the halcyon (calm, peaceful).

\section{Cultural AnAlysis of THE DifFERENCES IN ENGLISH AND CHINESE VOCABULARY}

\section{A. Different Cultural Backgrounds.}

People often cite the history, legends, literature, religious figures or events. It is the story of these characters and events that enrich the word meanings. The two peoples English and Chinese both have a long cultural history, and thus the two languages have a wealth of idioms. They are like a mirror reflecting two distinct peoples of different cultural backgrounds. Western culture are from the two major cultural background or tradition: Greek and Roman classical tradition of medieval Christian and Hebrew tradition. A large portion of English History are from Greek mythology, such as "cut the Gordian knot". There are many allusions involving English characters and events from the AngloAmerican literary treasure, especially Shakespeare. Such as the Achilles heel, Pandora's box (a metaphor for disaster trouble, the bane of the source). For English-speaking people, almost all references are to the story by Shakespeare's day, but they are often not conscious of it, for example: forgive and forget (excluding hatred), All is not gold that glitters. 


\section{B. Different Geographical Environments.}

China and Britain are far apart, belonging to Asia and Europe. The different geographical, climatic conditions are bound to have a huge impact on their social development. Britain is a typical ocean-related island country with its navigation far-advanced in the world at that time, so many words in English are associated with sea. But China is a land country with its people mainly living on land. So many Chinese words reflect land life. For example, if someone spent too much money easily, there is a saying spend money like water in English, while in China we use the words "hui jin ru tu (spend money like mud)". Another example is the idiom "between the devil and the deep blue sea" in English and "jin tui wei gu (a valley both forward and backward)" in Chinese to show someone is in dilemma. The two pair of idioms fully illustrates the profound impact of the geographical environment on the English and Chinese language and its culture words presented. More English examples are as close as an oyster (secretive), to fish in the air (squaring the circle), to rest on one's oars (take a break), to clear the decks (ready to fight), know the ropes (know the secret). More Chinese examples are related to agriculture and "niu"(ox), which are good helper for working people. such as chui niu (horse talk), lao huang niu(work like a horse), li da ru niu (as strong as a horse) etc; Chinese people have a strong love for "niu", because they play a very important role in agriculture. While in England, horese are more popular. More idioms like Ки ти feng chun (the dead wood rejuvenate in the spring), Rui xue zhao feng nian (Spring snow means a good harvest) and so on.

\section{Different Religion}

Religion is a very important part in ideology, which will exert a strong influence on our language. "The dove of peace" oringinates the story of Noah's Ark, sybolizes hope of peace. Cast pearls before swine come from Chapter 7 (Matthew in the New Testament), separate the sheep from the goats is from the Old Testament. More examples are God helps those who help themselves.

In Chinese, a lot of words are related to Buddism, which has a history of more than 1000 years in China. People believe that Buddha (fo) governs all, so many idioms are associated with Buddha. E.g. jie hua xian fo (to borrow flowers to give Buddha in order to show respect), lin shi bo fo jiao (ask for Buddha's help when nedded), mou shi zai ren, cheng shi zai tian (Man proposes, God disposes.)

\section{Different Social Customs}

Language closely realated to our social activities. So a lot of words are rooted in our social customs. The customs of different peoples differ greatly. It is the idiomatic part of a language that is the most difficult part for a foreigner to master. There are great differences between English and Chinese customs. The most typical examples lies in the connotional meanings of different animals. For example, in chinese culture, "gou"( $(\mathrm{dog})$ is regarded as a low-down animal, most idioms associated with "dog" imply derogatory meanings, such as "gou han jian", "lang xin gou fei". But in English culture, dog is deemed to be our faithful friends, so westerners usually look them equal to human beings. Therefore, phrases like top dog, lucky dog, big dog, are widely used in English. There is a quite famous saying: Love me, love my dog. Magpie is a king of lucky bird, but in English it's a noisy bird, even a chatter.

\section{E. Different Values}

Different values are due to the formation of social structure, social environment, cultural heritage and other factors.Cultural values guide our views and behaviours, therefore affect our communication. The values of East and West vary widely due to the impact of their own culture and traditions. Take individualism as an example. In Modern Chinese Dictionary, it refers to a false thinking that puts one's own benefits before mass benefits, which is opposite to chinese main culuture - collectivism, thus gives the word a negative sense "selfish". But in Western culture, individualism is a social theory advocating the liberty, rights, or independent action of the individual (from The New Webster's Encyclopedic Dictionary of the English Language). It emphasizes one's own personality and dignity, everyone has the right to choose one's own life. It doesn't include derogatory meaning at all.

Many English and Chinese idioms clearly reflect the two peoples' opposite philosophy of life. In Chinese culture, the Confucianism teaches people to be "satisfied with the state you have", to abide by the "moderate", Taoism teaches people to have "pure inaction", "be contented and happy," This feature is fully reflected in the following idioms: "Junzi yuyu yi, xiaoren yuyu li"'(Gentlemen fights for righteousness, small man fights for profits), "Junzi bu qu bu yi zhi cai"(you cannot get something that does not belong to you), "zhi zu chang le" (contentment with life) and so on.

\section{CONCLUSIONS}

This article analyses the cultural differences between English and Chinese words that embody in different ethnic thinking, social customs, religion and different values. It strives to help to overcome the obstacles in intercultural communication.

\section{References}

[1] Wang Xin. An Intercultural Study of English and Chinese Brand Translation [J] Border Economy and Culture, 2010,02: 99-100.

[2] Yang Genpei. Translation of English Idioms [J] Intercultural Perspective Forum on Contemporary Education (teaching and research), 2010,12: 83-85.

[3] Deng Dongyuan. Intercultural Perspective Differences between English vocabulary using $[\mathrm{J}]$ Yunnan Normal University (Teaching and Research on Chinese as a Foreign Language Edition), 2007,06: 66-69.

[4] Wang Ping. An Intercultural Perspective English Animal figurative meaning conveyed $[\mathrm{J}]$ insurance Vocational College, 2007,03: 88-90.

[5] Zhang Taomin. Intercultural Perspective of English and Chinese words in the translation [J] Science and Technology Information, 2012,32: 204. 